\title{
La enseñanza de la interpretación actoral del verso del teatro clásico español
}

\section{Artículo de reflexión}

\section{Javier J. González Martínez}

Universidad Internacional de La Rioja, España javier.gonzalezmartinez@unir.net

\section{Elia Muñoz Ruiz}

Escuela Superior de Arte Dramático de Castilla y León, España

melia.munrui@educa.jcyl.es

Recibido: 13 de agosto de 2018

Aprobado: 30 de octubre de 2018

Cómo citar este artículo: González Martínez, Javier; Muñoz Ruiz , Elia (2020). La enseñanza de la interpretación actoral del verso del teatro clásico español. Calle 14: revista de investigación en el campo del arte 15(27). pp. 96-107. DOI: https://doi. org/10.14483/21450706.15414

\section{(ㄷ) (1)}

https://creativecommons.org/licenses/by/4.0/deed.es 
Pedro Calderón de la Barca

8

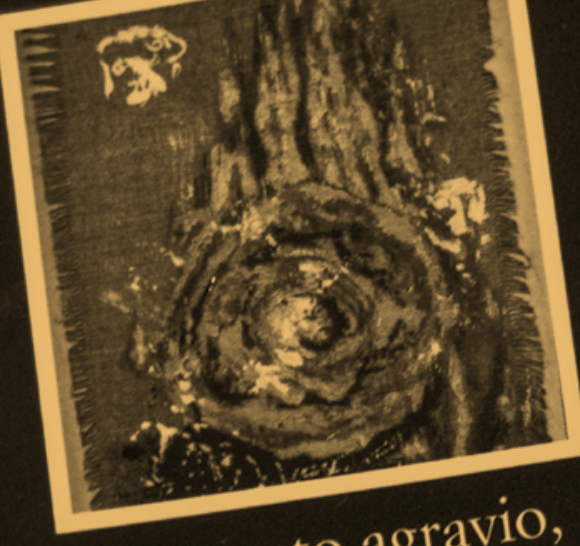

A secreto agravio, secreta venganza

dición de

Erik Coenen

CATEDRA

Letras Hispánicas

Pedro o

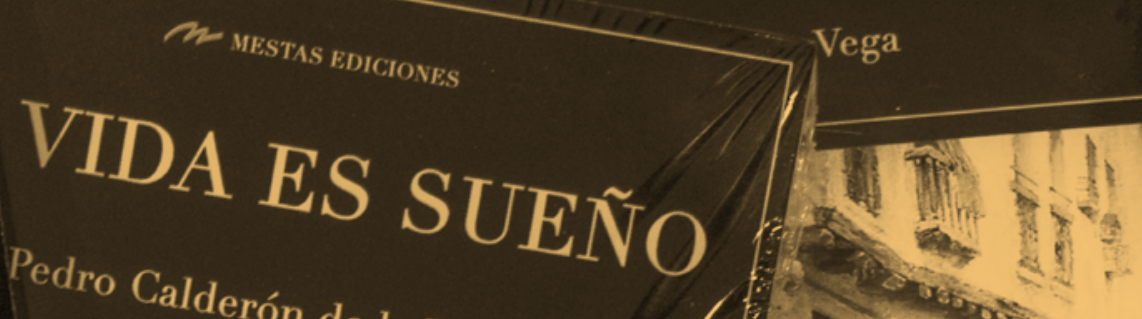

\%

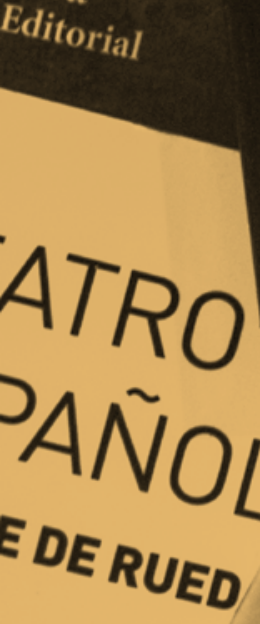

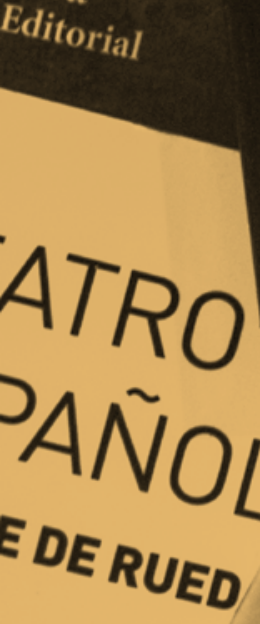

BF

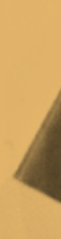

Lope de Vega Los cautivos de Argel

Edición de

Natalio Ohanna
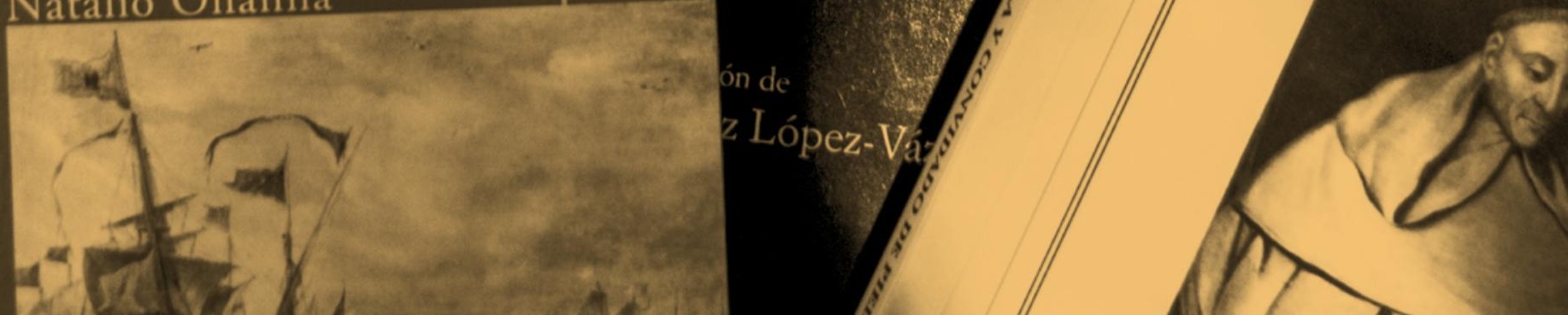


\title{
Resumen
}

Nuestro objetivo es analizar la formación actoral en verso del teatro clásico español en la enseñanza artística superior de arte dramático en España en la actualidad. El método de análisis empleado es el del verso integrado en la interpretación. Como resultado de este estudio, se identifica una nueva generación de profesionales del verso clásico, se definen sus características y se proyecta su posible camino escénico. Al mismo tiempo, se señalan las causas que han posibilitado esta nueva etapa y el marco académico y escénico en el que se desarrolla: institucionalización de la enseñanza teatral, conexiones con otros ámbitos europeos y normalización de las relaciones entre los estudios teóricos y la práctica escénica. Este estudio, dirigido especialmente a pedagogos, artistas teatrales y personas interesadas en el teatro clásico español, es un puente entre lo académico y lo escénico.

\section{Palabras Clave}

Arte dramático; educación artística; enseñanza actoral; interpretación del verso; teatro clásico español

\begin{abstract}
Our objective is to analyze the training in verse recitation for the Spanish classical theater in the higher artistic education for drama in Spain today. The method of analysis we use requires the poetry to be integrated in the performance. As a result of this study, a new generation of professional performers for the classical verse is identified, its characteristics are defined and its possible path on the stage is projected. At the same time, the causes that have enabled this new era and the academic and stage framework in which it develops are further described: formalization of theatrical education, connections with other European scenes and normalization of the relations between theoretical studies and stage practice. This study, especially aimed at drama teachers, performers and an all those interested in classical Spanish theater, builds a bridge between Academia and the stage.
\end{abstract}

\section{Keywords}

Drama; artistic education; acting training; verse recitation; Spanish classical theater

\section{Résumé}

Notre objectif est d'analyser la formation en récitation de poésie pour le théâtre classique espagnol dans l'enseignement artistique supérieur du théâtre en Espagne aujourd'hui. La méthode d'analyse que nous utilisons nécessite l'intégration de la poésie dans l'interprétation. À la suite de cette étude, une nouvelle génération d'acteurs professionnels du vers classique est identifiée, ses caractéristiques sont définies et son chemin possible sur la scène est projeté. En même temps, les causes qui ont permis cette nouvelle ère et le cadre académique et scénique dans lequel elle se développe sont décrits plus en détail : formalisation de la formation théâtrale, liens avec d'autres scènes européennes et normalisation des relations entre études théoriques et pratique théâtrale. Cette étude, spécialement destinée aux professeurs de théâtre, aux acteurs et à tous ceux qui s'intéressent au théâtre classique espagnol, constitue un pont entre l'université et la scène.

\section{Mots clés}

Drame ; éducation artistique ; formation d'acteurs ; récitation de versets ; théâtre classique espagnol 
O ensino da recitação dos versos para o teatro clássico espanhol

\section{Resumo}

Nosso objetivo é analisar o treinamento em recitação de versos para o teatro clássico espanhol na educação artística superior do drama na Espanha hoje. O método de análise que usamos requer que o verso seja integrado no desempenho. Como resultado deste estudo, uma nova geração de atores profissionais para o verso clássico é identificada, suas características são definidas e seu possível caminho no palco é projetado. Ao mesmo tempo, as causas que possibilitaram essa nova era e o quadro acadêmico e de estágio em que ela se desenvolve são ainda mais descritas: formalização da educação teatral, conexões com outras cenas européias e normalização das relações entre estudos teóricos e a prática dos estágios. Este estudo, especialmente destinado a professores de teatro, artistas e todos os interessados no teatro clássico espanhol, é uma ponte entre a Academia e o palco.

\section{Palavras-chave}

Drama; educação artística; treinamento em atuação; recitação de versos; teatro clássico espanhol

\section{Lachachiska rimangapa actoral chi verso teatro clásico español}

\section{Maillallachiska}

Nukanchipa kauai kanmi imasami kallari teatro clásico español chi iachaikui allilla ruragkunaauamanda chi suma rurag españapi kunaura. Imasami kauanchi ruraska iachachiska Rimangapa. Chi kauaska iachaikuskak, kauarinmi sug musu profesionalkuna verso clasicomanda, kauarinmi i llugsinmi sug ñambi escénico. Chasallata kauarinmi imasa riska musu etapapi chi iachaikuska escenapi llugsirirka: institucionalización iachaska teatral, Rimanakuska europeokunaua chasak kangapa allilla aiachiakuna Rimaipi i ruraipi. Kai iachai kauachiska pedagogokunata,allilla rurag teatralkuna i runakuna munagkuna teatro clásico españolpi,kanmi sug chaka academicomanda i escenicomanda.

\section{Rimangapa Ministidukuna}

Sumarurag dramático; iachaikuska astistica; iachachiska actoral; rimarii del verso; teatro clásico español 
Ha sido largo en el tiempo y en las argumentaciones el debate sobre la forma de decir el verso en el teatro clásico español. También se lo hemos leído a críticos y por eso Fernán-Gómez (1998, p. 127) decía con sorna: “Los críticos sí saben cómo deben decirse los versos en el escenario, y por eso llevan muchos años advirtiendo que, cuando se representa teatro clásico español, el teatro del barroco, los actores solemos decirlos bastante mal. Pero, desdichadamente, los críticos, que sí saben cómo deben decirse los versos y por ello perciben cuándo se dicen mal, no están capacitados —ni es su obligaciónpara enseñarnos a los actores a decirlos bien".

Aquí dejaremos a un lado la separación entre críticos y directores, entre académicos y prácticos, para analizar cómo aprenden hoy los futuros actores a interpretar el teatro en verso. En concreto, analizaremos el camino que se está emprendiendo en las materias de verso en las enseñanzas artísticas superiores españolas. Este análisis tiene factores positivos y negativos. Lo positivo es que se compartirá una forma de enseñar a interpretar el verso y se dejará un testimonio que servirá de reflejo de la perpetuamente cambiante historia del teatro. Lo negativo es la perennidad de esta forma de enseñar. Lo explica claramente Oliva (2009, p. 138): "si las diferencias de la interpretación actual con la de hace apenas cincuenta o sesenta años son ya apreciables, qué no lo serán con las de hace trescientos o cuatrocientos".

El objetivo de las siguientes páginas no es específicamente la métrica, la rítmica, la entonación, sino que se trata de la enseñanza actual del verso clásico español. Por lo tanto, no nos detendremos en el arte de la interpretación del siglo XVII, ya estudiado por Rodríguez (1998), ni atenderemos al juego actoral actual. La justificación de este objetivo viene dada porque, como dice Mascarell (2016, p. 72), nadie pone en duda la necesidad de la formación para el trabajo con el verso "aunque todavía falta la implantación definitiva de asignaturas específicas de verso clásico en muchas escuelas del territorio español". Sin embargo, en algunas escuelas, la enseñanza del verso clásico es una materia troncal en la especialidad de interpretación. Aquí ofrecemos un panorama y un análisis de esta enseñanza.

Para conocer la trayectoria que ha tenido el estudio del verso desde el origen de las escuelas de arte dramático en España puede consultarse la sucinta historia que traza Peláez (2001, pp. 271-274). También puede interesar al curioso lector el repaso que hace Granda a los referentes de la enseñanza y ejercicio de la dicción del verso en los siglos XIX y XX: Isidoro Máiquez, Carlos Latorre, Julián Romea, Matilde Díez, Teodora Lamadrid, Mariano Fernández, Rafael y Ricardo Calvo, Antonio Vico, Elisa Boldún, Emilio Mario, María Tubau, María Guerrero, Fernando Díaz de Mendoza, Emilio Thuiller, Cipriano de Rivas Cherif, José Estruch, José Luis Alonso, Manuel Dicenta, Carmen Seco, Salvador Soler Marí y María Jesús Valdés. Esta sumaria historia del verso es publicada en el año 2000 y acaba con estas palabras: “Existe una nueva generación que empieza a descubrir el sentido del verso, a ellos está encomendado el futuro y yo creo con firmeza que ese futuro ha de beneficiar al verso y al teatro en general" (Granda, 2000, p. 100). Desde este punto tomamos el testigo en este artículo.

Durante un tiempo la formación de los actores en relación al verso era prácticamente nula: se veían obligados a guiarse por su intuición (véase el testimonio de la actriz María Carrillo sobre su experiencia teatral en España entorno a 1950 en Peláez 2001, p. 275). Los actores aprendían la interpretación de verso a través de la misma práctica escénica de los ensayos previos al estreno. Según Mascarell (2016, p. 69) había dos opciones en la España del siglo XX: "la declamación ampulosa que enfatiza la rima y los componentes versales, y los que desean gozar del teatro barroco en un marco interpretativo cercano al naturalismo".

Granda (2000, p. 82) ha demostrado la importancia que tuvo la institucionalización de la enseñanza teatral para la historia del teatro español en verso. Este prestigio de la educación dramática se multiplica en España desde 1992 al elevar estos estudios al nivel superior, el mismo que tenían reconocido en el resto de Europa (Real Decreto 754/1992). Pero el gran cambio se está dando desde 2006, año en el que las enseñanzas artísticas superiores se incorporan al Espacio Europeo de Educación Superior (Ley Orgánica 2/2006). El nuevo marco educativo ha creado puentes entre las universidades y las escuelas, entre la investigación y la enseñanza, entre los estudios teóricos y la práctica escénica. Es un buen momento para detenerse y analizar lo que está suponiendo para el teatro en verso la implantación del marco de enseñanza artística superior de arte dramático y cómo ha afectado a la formación actoral. Estamos en los inicios de la plasmación escrita de esta nueva etapa de la enseñanza teatral. Tiene razón Rodríguez) cuando destaca “las dificultades para acomodar en el espacio académico una propuesta pedagógica y un modelo de investigación coherentes con un sentido complejo de práctica escénica que 
recupere la síntesis del doble código — visual, textual. (2012, p. 20).

Como veremos en la segunda parte de este artículo el aprendizaje contemporáneo combina la musicalidad y el movimiento, el oído y la vista, la palabra y el gesto. De ahí que una de las asignaturas fundamentales para la enseñanza del verso en las escuelas de arte dramático se llame "Verso en acción". Los alumnos que llegan al estudio y ejercicio de esta oralidad del verso, han trabajado previamente la comprensión del texto y los recursos métricos, para cuyo estudio es especialmente recomendable el libro Dramaturgia y práctica escénica del verso clásico español de Susana Cantero.

Esta relación entre el verso y la acción está muy bien ejemplificada por esta experiencia actoral de Pedro Miguel Martínez:

[...] cuando estaba haciendo La vida es sueño -yo hacía Basilio - había un momento, para mí mágico, de la función, pero era del autor. Era el momento -después de que a Segismundo lo sacan de la cueva los soldados - en el que el pueblo lo aclama, la discusión con Clotaldo... toda esa escena hecha en redondillas; y de pronto aparece un momento de octavas reales en que ocurre la aparición del rey Basilio: '¿Quién, Astolfo, podrá parar, prudente, la furia de un caballo desbocado'. La ruptura rítmica es tan impresionante, que te lleva a otro ritmo escénico, a otro estado de ánimo. Sabes y adivinas muy fácilmente como actor, qué es lo que el autor te está pidiendo cuando pone esa versificación totalmente distinta. De pronto, si entramos en el palacio del rey Basilio, que está desesperado en ese momento, ¿qué emplea el autor en ese instante?, pues octavas reales. Los actores debemos saber qué significa de pronto ese cambio rítmico, musical, que está produciendo un maravilloso y necesario cambio dramático en ese momento de la función (Martínez, 1996, p. 333).

Esta imbricación entre palabra y acción ayuda a salvar uno de los primeros escollos en la formación actoral: la repulsa a lo que consideran el corsé del verso. “Gran número de actores no ocultan su prejuicio contra las leyes métricas. Solo ven en ellas una coraza impuesta a su personalidad" (García, 2016, p. 16). Sin embargo, el verso es precisamente lo que ayuda a los estudiantes a liberarse de la automatización lingüística. En el fondo se trata de enseñar a los futuros actores a desautomatizar el lenguaje. La memorización del texto clásico está en las antípodas de la repetición despersonalizada de unos versos. Es necesario "comprender la actividad, el dinamismo, la pulsión, el laboreo (Marina, 1998, p. 147) que subyace en la palabra. El lenguaje en el teatro está vivo, más vivo que fuera de la escena. $\mathrm{O}$ al menos, así debería ser. Y si esto es así con toda palabra en teatro, tiene que serlo de forma especial en el teatro en verso. Precisamente el artificio de la forma versal despierta y hace consciente la emisión y la recepción lingüística.

En la asignatura "Verso en acción" se enseña a los alumnos a enriquecer con signos extralingüísticos este lenguaje. El director de teatro clásico Miguel Narros sostenía que había que descubrir la musicalidad del texto para ejecutar la partitura del verso (Peláez, 2001, p. 277). Una vez que se capta esa musicalidad se puede bailar, se puede interpretar. Como dice López-Antuñano (2017, p. 156), para que un actor "diga el verso con naturalidad y sin encorsetamientos, al tiempo que no pierda la musicalidad, la fuerza expresiva de palabras e imágenes, las distintas velocidades del ritmo interno o el sentido entre el tipo estrófico y los sentimientos o motivaciones de un personaje en unas circunstancias dadas" ha de convertir ese lenguaje en vida. La comprensión del texto por parte del actor es necesaria para que posea organicidad y comunicabilidad.

Como en todo proceso de comunicación, también en el teatro en verso hay un emisor y un receptor. En las escuelas de arte dramático existen discentes que se preparan para ser actores. Pero no existen discentes para ser público exclusivamente. Queremos subrayar con esto que la comunicación es asunto de dos, por lo menos, y las escuelas superiores de arte dramático solo llegan a uno de los agentes. La escuela del espectador es el teatro y sus docentes son los actores. Es responsabilidad del actor tratar de hacer atractivo e inteligible el verso. Si los actores consiguen captar la atención del público, le sacarán del falso estado pasivo de escucha y le introducirán en un proceso tan activo como la propia habla. Pero como en todo proceso comunicativo, el correcto mensaje del actor será comprendido o no según la voluntad y capacidad del público.

\section{Perspectiva desde la enseñanza interpretativa del verso}

Las circunstancias que giran alrededor de la enseñanza del verso son variadas y muy personales, de ahí su enorme dificultad. Los profesores de la práctica del verso son portadores de una experiencia adquirida a lo 
largo de su carrera como actores y como docentes. Estas experiencias académica y artística han ido de la mano, no sería posible la una sin la otra, y no puede transmitirse exclusivamente a través del traspaso de información teórica. Tienen que transitar junto al alumnado un camino etéreo y subjetivo en muchos de sus aspectos.

Los profesores que imparten las asignaturas de verso en las escuelas superiores de arte dramático conocen el ámbito filológico y el escénico, ya que juntos conforman una realidad que se necesita y alimenta de manera mutua. No sería posible la investigación para el hecho escénico sin la valiosa ayuda que nos ofrece la filología, ya que fija y ayuda a comprender el texto. La antigua brecha entre los conocimientos literarios y la realización escénica, que separó la escena y la academia, es cada vez más estrecha. Por lo tanto, la investigación completa sobre el teatro clásico no excluye a nadie: necesitamos un estudio formal del texto y ser fieles a la propia esencia espectacular del teatro. Esta es su misión y, fuera de esto se convierte en una visión, que dependiendo de la opción que se tome, puede ser muy erudita o muy entretenida, pero dentro de una perspectiva con un horizonte incompleto al faltarle el trabajo conjunto.

Las obras teatrales exigen una interpretación que transforma la palabra escrita en realidad escénica que es vista y oída por el público. Esto es fundamental para entender los textos y contar la historia que se vive en ellos. Desde la perspectiva de la formación actoral, el teatro es considerado siempre "en pie". Los creadores escénicos ponen la obra de teatro en una nueva relación con nuestra época, porque necesitan hacer algo vivo. Desde este impulso de crear algo vivo y actual en el teatro, se desbrozará y argumentará el trabajo con el verso en los territorios antes mencionados: el conocimiento literario, la experiencia artística y la pedagogía.

Como se comentó más arriba, tomamos el testigo de Granda (2000) para testimoniar la historia del teatro en verso en el siglo XXI. Muchos de los actuales profesionales de la escena y la enseñanza se han formado en el verso clásico del Siglo de Oro español de la mano de Vicente Fuentes en la Real Escuela Superior de Arte Dramático (RESAD). El camino de aprendizaje consistía en la aplicación del teatro físico al teatro textual. Se trata del entrenamiento somático, en el que la palabra y el cuerpo caminan de la mano, son dos aspectos de un todo: el actor y la actuación.

A finales del siglo XX Vicente Fuentes formó a generaciones de alumnos de la RESAD, entrenó el movimiento, la expresión corporal, la voz y el verso, de forma que creó un nuevo concepto de trabajo del teatro clásico. Este comienzo fue la prehistoria de lo que más tarde, en el año 2004, sería la metodología de la Joven Compañía Nacional de Teatro Clásico, en la que Fuentes, junto con otros profesores, desarrollaron una manera de trabajar que ha influido y cambiado el rumbo y la forma de entender la práctica del verso, también en lo referente a la pedagogía en las escuelas superiores de arte dramático. Gracias a este nuevo camino un grupo de jóvenes actores y profesionales de distintos ámbitos emprendieron la investigación y escenificación del teatro clásico. La importancia y novedad estribaba en que esta forma era eminentemente práctica y colaborativa.

Teniendo en cuenta que había muy poco escrito y publicado sobre la enseñanza del verso, los comienzos tuvieron poca base teórica. Se contaba solo con el método de Josefina García Aráez, que publicó su manual en 1997 y acaba de ser reeditado en 2016. Esta carestía, que podía haber sido un obstáculo, dio la posibilidad de empezar con enorme libertad y permitió una participación especialmente inspirada y creativa. Esta forma de aprendizaje fue la primera piedra en el camino que llega hasta hoy y que ha unido a muchos profesionales de la escena actual: iluminadores, sonidistas, coreógrafos, vestuaristas, filólogos, especialistas en movimiento, lucha escénica y muchos que han puesto su experiencia y dedicación al servicio del teatro clásico.

Esta forma de trabajar fue posible porque los primeros discentes y futuros docentes tenían algo en común: el entrenamiento. Las horas de dedicación al entrenamiento compartido son la piedra angular que sostiene este trabajo artístico. El entrenamiento configura un territorio dramático donde un grupo de profesionales se relaciona con sus herramientas de trabajo, afina sus instrumentos, prueba y falla para desarrollar sus habilidades. Se ponía esfuerzo en trabajar juntos, en sintonía, para crear un elenco que caminara en armonía. El estudio formal del verso se hizo inseparable del entrenamiento actoral y del sistema de actuación que tuviera cada uno. Siempre es necesaria una metodología de actuación que dé soporte, ya que el resultado final es la creación de personajes que mantendrán tensos conflictos y se enfrentarán a obstáculos aparentemente insuperables. El teatro clásico trata temas que nos importan, que nos sitúan en el plano de lo más profundo del ser humano. Grandes son las emociones y grandes son las palabras que las conducen. $Y$ van juntas. Como dice Declan Donnellan (2004, p. 60) en el teatro las apuestas deben ser siempre altas. 


\section{Panorama actual de los profesionales del verso teatral}

Estos profesionales van a acabar actuando y trabajando en diferentes compañías, festivales y centros de enseñanza artística. Haremos una rápida relación. Elia Muñoz, que se formó en la RESAD y es profesora de voz y verso en la Escuela Superior de Arte Dramático de Castilla y León (ESADCYL), participó en el primer taller dirigido por Vicente Fuentes que dio como fruto el montaje de El amor enamorado de Lope de Vega. Pepa Pedroche, conocida actriz y ahora directora en la Compañía Nacional de Teatro Clásico (CNTC), también participó en ese primer taller y continuó en el segundo montaje, La discreta enamorada de Lope de Vega.

Estaba también en esos comienzos Paco Rojas, que después fue asesor de verso, lector seleccionador de obras y participó en numerosos montajes con la CNTC y otras compañías privadas. En la actualidad también enseña verso en El Laboratorio, escuela fundada por William Layton. Otra actriz y pedagoga que formó parte de aquel proyecto es Chelo García, en la actualidad profesora de verso en la RESAD. Y, por último, José Luis Torrijo participó en esos talleres y ha sido actor de muchas obras clásicas, además de trabajar en el proyecto del Teatro de La Abadía. José Luis Gómez, promotor de este proyecto, es también una referencia esencial en el asentamiento del entrenamiento actoral como norma del trabajo de texto y forjador de una pedagogía puntera de la interpretación de los textos clásicos. Fueron muchos los actores, formados en la RESAD y especializados en esos talleres, que se han convertido en profesores de verso de distintas escuelas.

En el entorno de Vicente Fuentes, de la RESAD, de la Joven Compañía de Teatro Clásico y del proyecto de La Abadía estaban, entre otros muchos, los siguientes actores y directores: Gabriel Garbisu, Joaquín Notario, Óscar Zafra, Ernesto Arias, Eduardo Navarro, Lidia Otón, Miguel Cubero, Alberto Jiménez, Carmelo Gómez, Carmen Machi, Blanca Portillo, Elísabet Gelabert, Rosa Manteiga, Israel Elejalde, Luis Moreno y Miguel del Arco. Muchos de ellos vertebran las compañías de teatro actualmente e imparten cursos de formación en todos los niveles.

Muchas también han sido las compañías de teatro que han surgido por iniciativa de los actores y directores que practicaban su manera de ver el teatro clásico en talleres y laboratorios dedicados a la investigación de la actuación en verso. Uno de los hitos más conocidos es Fundación Siglo de Oro, anteriormente llamada
Rakatá, creada por Rodrigo Arribas, Javier Ortiz y Alejandra Sáenz, en la que colaboraron directores como Carlos Aladro, actual director del Festival de Otoño de Madrid, y Laurence Boswell, que también ha dirigido en la Royal Shakespeare en el marco del ciclo de teatro áureo español. Gabriel Garbisu creó la compañía Amara Teatro, de la que se recuerdan sus puestas en escena calderonianas: El astrólogo fingido y La vida es sueño. Los componentes de estas compañías, junto con otras en contacto, como Nao D'amores, dirigida por Ana Zamora, compartían un lenguaje común que les permitía una comunicación plena y la consecución de un estilo que ha definido su manera de "decir el verso".

\section{La experiencia somática del verso}

Esta expresión, "decir el verso", se ha convertido en un lugar común, en el doble sentido: es usada por muchos y comprendida por pocos. Para esta generación que se formó a finales del siglo XX, ha actuado a caballo del XX y XXI y enseña en el XXI, este "decir el verso" son las reglas iniciales básicas que son necesarias para superar las diferencias entre las distintas maneras de decir. Estas reglas no son unas normas rígidas e inflexibles sino que forman un lugar de encuentro en los primeros entrenamientos. Este lugar de encuentro comparte, entre otras, las siguientes premisas: el verso es una herramienta que ayuda al actor, el ritmo y la música son algo natural al verso, la base del trabajo teatral es el placer del verso y, por último, la conveniencia de diferenciar lo objetivo de lo subjetivo en cuanto al habla y el verso, lo que es hábito personal de lo que es experiencia universal.

De esa investigación surge la idea de un ritmo estándar que se denomina "marca rítmica", que siempre está en la base del trabajo del octosílabo, que aporta un ritmo común y compartido. Crear este lenguaje común y compartido permite consolidar un elenco capacitado, en continua investigación y que no parta de cero cada vez que comienzan los ensayos de una producción.

Cuando se experimenta con la palabra en el teatro, ya sea en verso o en cualquier otra forma, no se puede desligar el lenguaje de la acción física que lo sustenta. El lenguaje por sí mismo no aclara, ni resuelve el problema de la interpretación de la partitura-texto. Para convertirlo en habla es necesario comunicar desde el motor del cuerpo y transformar las palabras en pensamientos en acción. Al mismo tiempo el habla se da desde las circunstancias que rodean a los personajes y que se describen en el argumento de la obra. 
La estructura se desvela útil dentro de la experimentación del cuarteto que conforman cuerpo, voz, pensamiento y emoción. Los cuatro colaboran eficazmente en el entrenamiento instrumental del actor de manera equilibrada. La investigación desde el trabajo actoral aporta esa parte creativa del lenguaje y es imprescindible para el arte. Esta indagación con el lenguaje en verso surge de la interacción entre el cerebro y el cuerpo. Por eso se dice que el primer escenario del teatro en verso es la propia carne del actor.

En el teatro las palabras no definen unilateralmente el sentido, ni el sentimiento, ni la acción. Las palabras cuentan con la fisiología del sujeto creador (actor) y con el carácter somático de su origen (personaje). Como dice Antonio Damasio: "La mente acecha a la carne, y los humanos sacamos los estados anímicos de los músculos" (citado en Lehrer, 2010, p. 41). Partiendo de esta premisa, la investigación sobre el lenguaje pasa por "el cuerpo en movimiento". Al imaginar un estado corporal específico, la mente puede inducir sus propias emociones. El actor crea un estímulo poderoso que desencadena de forma automática y consciente una ola de cambios que moverá el cuerpo a la acción. Es la comunicación a través del canal del cuerpo. La mente es capaz de crear el "como si mágico", el espacio creado a través de la imaginación que posibilita la interpretación para que el cuerpo experimente un acontecimiento físico real.

Los estudiantes de arte dramático formados de esta manera practican desde una técnica de actuación y experimentación sensible del cuerpo que está al servicio del lenguaje. Esto les lleva a descubrir y expresar la profundidad del teatro clásico español. La fisiología del verso les acompaña desde el comienzo de sus estudios a través del entrenamiento instrumental. En concreto, el primer paso de este entrenamiento comienza con la fijación de la base rítmica de los versos, marcada por la sístole y diástole de su propio corazón. De esta forma el octosílabo, tan usado en nuestra métrica, se convierte en fiel aliado de nuestra respiración como grupo fónico.

\section{Obstáculos en el aprendizaje}

La primera y enorme dificultad que sale al paso en este proceso de enseñanza y aprendizaje tiene su origen en los prejuicios de algunos estudiantes en relación al teatro clásico: tienen la idea de que es antiguo, aburrido, ininteligible y carente de interés para el hombre posmoderno. El profesor debe comenzar por crear ese interés y los años de docencia han demostrado que su gran aliado es el argumento de las obras. Los argumentos son apasionantes y los personajes no son tan diferentes a nosotros: aman, se desprecian, desean, odian, persiguen su supervivencia y sienten de manera similar a nosotros. Un estudiante de sensibilidad artística crea desde estos parámetros un primer vínculo, que una vez practicado se vuelve sólido y permanente, pues su condición de actor le hace encarnar personajes y situaciones.

La siguiente dificultad tiene que ver con el lenguaje y es más ardua de solucionar por el alejamiento que existe entre su habla cotidiana y el lenguaje en verso del siglo XVII. Se hace necesario explicar estructuras sintácticas y acudir a diccionarios hasta llegar a la fase de "comprendo todo lo que leo". Para llegar aquí se utiliza un recurso llamado "texto analógico" que consiste en traducir a su habla actual el texto. De esta manera es fácil para ellos comprender donde está el impulso que lanza ese pensamiento liberando su expresión más genuina. Se hace con pensamientos enteros y a veces con algunas palabras complicadas y en desuso en la actualidad. Activamos la voluntad expresiva desde la palabra y la acción.

A esto se suma que muchos estudiantes no tienen aún la capacidad para identificar y nombrar los procesos emocionales de los personajes, lo cual incrementa su dificultad para reconocerlos y comunicarlos. Por eso su lenguaje se vuelve indefinido y no pueden comunicar con claridad. Esta falta de precisión afecta a su competencia para generar impulsos "sentipensantes" (Ocampo, 2013, p. 18). Esto merma y limita los cambios que tiene que producir el pensamiento en su expresividad, tanto en su respiración, como en los impulsos físicos. Sin estos cambios previos no puede darse el acto de la comunicación a través del verso. Abunda sobre este aspecto desarrollado por la somaestética Petersen en su reciente Women's Somatic Training in Early Modern Spanish Theater.

De ahí surge la necesidad de elaborar un entrenamiento que integre lo físico y la palabra desde el inicio de su aprendizaje. Se dedica mucho tiempo a analizar la estructura del texto en verso para llegar a lo expresivo. El estudio formal del verso comienza de forma sencilla. En primer lugar, se diferencia entre pautas técnicas y expresivas. A continuación, se va de lo técnico a lo expresivo para facilitar el trabajo de acercamiento y disfrute del lenguaje en verso. Por último, se busca un criterio común de manejo y expresión de la palabra dentro de la formalidad del verso. 
Las pautas técnicas requieren un conocimiento de la preceptiva métrica que aprenden en asignaturas como "Lenguaje versificado". Más adelante, en las asignaturas de "Verso en acción", adquieren práctica de expresión y los fundamentos de la investigación desde el sistema de actuación. Se trata de convertir todos los contenidos de estilo en material de actuación. De esta forma se produce el proceso de traducción que es propio de los actores. Por ejemplo, para un actor una coma no es solo un signo de puntuación que sirve para indicar una pausa breve, tiene que servir al actor/personaje para hacer un giro en su elucubración que manifieste otra línea de pensamiento o quizás para dudar sobre el punto de partida o destino de su argumentación.

Un encabalgamiento no es solo el desajuste de una pausa versal y una pausa morfosintáctica. Para un actor es importante encontrar la clave expresiva que justifique por motivos escénicos esa pausa versal. Como dice el actor Arturo Querejeta: “creo que en lo que más se debe insistir es en tener muy en cuenta la acentuación del verso, pero no 'golpearlo'; ser consciente de la rima como una realidad latente, pero evitar el 'rengloneo'; y entender que ese hilo de pensamiento que nunca debemos perder está basado en gran medida en el encabalgamiento, para mí, la base de toda la estructura versal" (Bastianes, 2014, p. 338).

El actor analiza los sustantivos y los verbos para definir los objetivos que persigue el personaje. Las palabras se trabajan para que puedan ejecutar el secreto de la acción que contienen y puedan hacer su función. Los impulsos físicos extraídos de las palabras traducen el patrón de la estrofa para entrar en el ritmo emocional del personaje. En definitiva, se descubren las claves que pautan los dramaturgos en el texto para que pueda llegar a tener vida escénica.

Un actor mide la cantidad, el peso y el tamaño de las palabras. La cantidad puede verse afectada por sinalefas. La continuación entre una palabra y la siguiente marcada por una sinalefa se debe fundamentar en un pensamiento en acción. De la misma manera que un verso compartido con otro personaje crea un vínculo entre ellos que tiene que ver con lo que les sucede. La longitud de un pensamiento que se prolonga en varios versos o incluso estrofas puede indicar la relevancia de su contenido para el personaje. Un pensamiento que discurre por varias estrofas podría indicar una enorme necesidad de transmitirlo y suele reflejar la intensidad del conflicto que soporta el personaje. De la misma manera el peso de las palabras que componen un verso, su localización al principio, en medio o al final, repercuten en el discurso. Analizar y entrenar el verso de esta manera abre el sentido, hace visible la partitura, pone de manifiesto el cariz espectacular del texto. La forma y el sentido siempre están en complicidad: la forma siempre es elegida en función del sentido.

Hablar en verso es fundamentalmente medir. La medida constituye gran parte del entrenamiento para hacer verso. Es lo que diferencia la prosa del verso. Para entrenar la medida en octosílabos se utiliza la marca rítmica. Se trata de jugar con un patrón estándar compuesto de nueve impulsos, los ocho de las sílabas, más el silencio para el octosílabo. De esta manera el oído del estudiante interioriza la secuencia que genera una musicalidad compartida por todo el elenco de actores. Sirva de modelo el siguiente ejemplo a partir del conocido verso de La vida es sueño, en el que los impulsos de las sílabas 1-4-7 corresponden a la base del tempo:

$$
\begin{aligned}
& \text { 1-2-3-4-5-6-7-8-9 (pausa versal) } \\
& \text { A-PU-RÁR-CIÉ-LOS-PRE-TÉN-DO }
\end{aligned}
$$

Una de las ventajas de esta práctica radica en que el estudiante transita cada una de las sílabas de las palabras que componen el verso de forma que les da el valor que todas ellas tienen. Al mismo tiempo se atiende a cada uno de los versos como una entidad propia que debe ser estudiada en su particularidad. De esta manera el estudio de la estructura, de la métrica y del lenguaje nos conduce inevitablemente a los niveles más profundos de la personalidad y comportamiento de los personajes.

Pondremos un último ejemplo que será clarificador de esta forma de enseñar y entrenar el verso del teatro clásico español. El objetivo es mostrar la relevancia del soporte somático como motor de la acción dramática del lenguaje en verso. Lo haremos a través de los versos en romance de Isabel en el comienzo de la tercera jornada de El alcalde de Zalamea de Calderón de la Barca. El estudio y la experimentación se hace solo sobre este fragmento de texto y este momento dramático y desde la exploración del lenguaje como estructura formal y expresiva. Estas palabras generarán unas imágenes. Estas imágenes están ligadas a una expresión. Esta expresión hace surgir un movimiento físico. Y, por último, este configura la acción.

El monólogo de Isabel nos da cuenta de la situación doliente y peligrosa en la que se encuentra debido al rapto y violación que ha sufrido por parte del capitán, 
del que, finalmente, y tras un largo periplo nocturno, ha conseguido huir. En esta ocasión no nos detendremos en el estudio de la métrica y su estructura formal. Lo que nos ocupa ahora es el viaje de lo somático a lo expresivo. Y se parte de una pregunta: ¿por qué habla con el sol? ¿De dónde surge la necesidad de hablar con el sol?

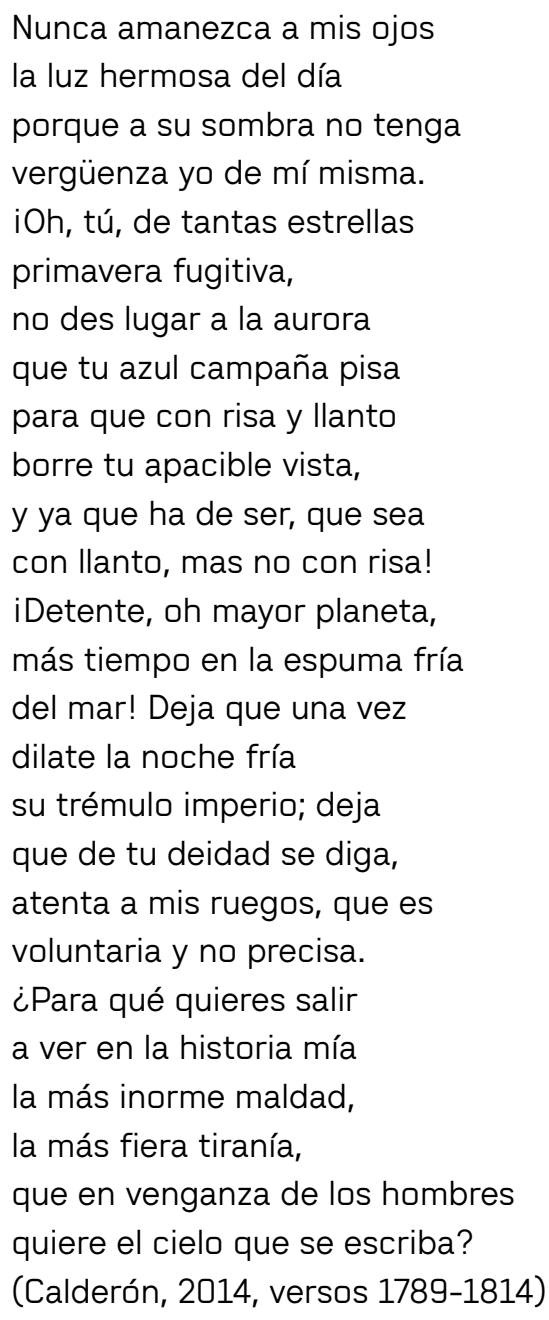

Una actriz que interprete este papel debe buscar el sentido de dirigirse desde un primer momento al sol como único interlocutor. Por el contexto en el que estamos, por lo que ha sufrido Isabel, buscar en esta ocasión un exclusivo sentido retórico o estético carecería de interés y pertinencia dramática. Desde luego, las palabras y la construcción son bellas, pero la respuesta es física. Isabel lleva corriendo toda la noche, huyendo después de sufrir la violación. Está terriblemente cansada, física y moralmente. Este estado de decaimiento del cuerpo y del espíritu hace que en un momento determinado se pare y justo ahí se produce una conexión sensorial con el amanecer, un fenómeno cotidiano que se le revela extraordinario.

Mas, iay de mí!, que parece

que es fiera tu tiranía, pues desde que te rogué que te detuvieses, miran mis ojos tu faz hermosa descollarse por encima de los montes. iAy de mí, que acosada y perseguida de tantas penas, de tantas ansias, de tantas impías fortunas, contra mi honor se han conjurado tus iras! (Calderón, 2014, versos 1815-26)

Es tal su estado de abatimiento y de ausencia de barreras intelectuales, que es capaz de recibir con toda su belleza el éxtasis de la salida del sol. Al mismo tiempo que observa el amanecer, percibe que la luz empieza a descubrir todo lo que la noche ocultó.

¿Qué he de hacer? ¿Dónde he de ir?

Si a mi casa determinan

volver mis erradas plantas

será dar nueva mancilla

a un anciano padre mío,

que otro bien, otra alegría

no tuvo sino mirarse

en la clara luna limpia

de mi honor, que hoy, idesdichado!, tan torpe mancha le eclipsa.

Si dejo, por su respeto

y mi temor afligida,

de volver a casa, dejo

abierto el paso a que diga

que fui cómplice en mi infamia,

y ciega y inadvertida

vengo a hacer de la inocencia

acreedora a la malicia.

(Calderón, 2014, versos 1827-44)

Con la llegada de la luz cae realmente en la cuenta de lo que va a suponer para ella enfrentarse a ese nuevo día. Empieza a calibrar las consecuencias de su estado y a elucubrar acerca de las posibles soluciones. En este ejemplo hemos visto que necesitamos la conjunción de signos lingüísticos y extralingüísticos para alcanzar el sentido de esta acción. El lenguaje oral es un medio insuficiente para descubrir y describir la acción, porque es una ordenación lineal de ideas sucesivas, mientras que en un proceso todos los elementos que intervienen cambian a la vez y se influyen conjuntamente. Las palabras adquieren valor real si las compartimos en una experiencia similar dentro de un proceso. Sirven entonces de títulos para identificar sensaciones comunes. 
En fin, este análisis de la enseñanza de la interpretación actoral del verso del teatro clásico español en una escuela superior de arte dramático del Espacio Europeo de Educación supone la plasmación por escrito de una forma actual de decir el verso. Con esta exposición de unos principios de pedagogía teatral del verso se cubre una carencia que tenía la bibliografía de esta materia. La incorporación de los estudios artísticos teatrales al nivel superior de educación está acercando al mundo académico las propuestas pedagógicas y los modelos de investigación de la práctica escénica. Muchos de los conceptos y sistemas utilizados en la enseñanza actual han sido heredados de una tradición oral secular. Otros han sido originados por una nueva hornada de actores y profesores que comparten su experiencia en las tablas con un nuevo marco educativo. La brecha entre la escena y el ámbito educativo queda a partir de ahora más reducida. La creación de este lenguaje común permitirá una mejora en la comunicación.

\section{Referencias}

Bastianes, M., Fernández, E. y Mascarell, P. (2014). "Entrevista a Arturo Querejeta", en M.

. (eds.), Diálogos en las tablas. Últimas

tendencias de la puesta en escena del teatro clásico español. Kassel: Edition Reichenberger, pp. 336-38.

Calderón de la Barca, P. (2014). El alcalde de Zalamea. I. Arellano (ed.). Colección Teatro clásico español, Canon 60, Cervantes Virtual. Disponible en: «http://www. cervantesvirtual.com/obra/el-alcalde-de-zalamea-0/» Consultado en junio de 2018.

Cantero Garrido, S. (2006). Dramaturgia y práctica escénica del verso clásico español. Madrid:

Fundamentos.

Donnellan, D. (2004). El actor y la diana. Madrid: Fundamentos.

Fernán-Gómez, F. (1998). El tiempo amarillo. Memorias ampliadas (1921-1997). Barcelona: Debate.

García Aráez, J. (2016). Verso y teatro: guía teóricopráctica para el actor. Madrid: Fundamentos.

Granda Marín, J. J. (2000). “Calderón, los cómicos $y$ el verso en el siglo XX", en J. M.
Díez Borque y A. Peláez (eds.), Calderón en escena: siglo XX. Madrid: Consejería de Cultura de la Comunidad de Madrid, pp. 79-100.

Lehrer, J. (2010). Proust y la neurociencia: una visión única de ocho artistas fundamentales en la modernidad. Barcelona: Paidós.

López-Antuñano, J. G. (2017). “Ignacio García: el humanismo convertido en arte en las escenificaciones", en M. Hoyo Ventura (ed.), La escenificación española contemporánea. Granada: Ediciones Tragacanto, pp. 143-60.

Marina, J. A. (1998). La selva del lenguaje. Barcelona: Anagrama.

Martínez, P. M., Marzoa A. y Peláez A. (1996). “El actor y la actriz ante el teatro clásico", en A. Serrano (ed.), En torno al teatro del Siglo de Oro: XII-XIII Jornadas de Teatro del Siglo de Oro. Almería: Instituto de Estudios Almerienses, pp. 319-36.

Mascarell, P. (2016). “De la polémica al equilibrio. Notas sobre la dicción del verso y la adaptación del texto en la puesta en escena actual del teatro clásico español", en Cuaderno de Investigación Filológica, 42, pp. 67-80. DOI: 10.18172/cif.3053

Ocampo Guzmán, A. (2013). La libertad de la voz natural: El método Linklater. México: Universidad Nacional Autónoma de México.

Oliva, C. (2009). Versos y trazas. Murcia: Universidad de Murcia.

Peláez, A., Carrillo M., Curieses A. y Maya, J. (2001). “El actor: técnicas de representación", en A. Serrano (ed.), En torno al teatro del Siglo de Oro: XV Jornadas de Teatro del Siglo de Oro. Almería: Instituto de Estudios Almerienses, pp. 271-78.

Petersen, E. C. (2017). Women's Somatic Training in Early Modern Spanish Theater. Nueva York: Routledge.

Rodríguez Cuadros, E. (2012). El libro vivo que es el teatro. Canon, actor y palabra en el Siglo de Oro. Madrid: Cátedra.

(1998). La técnica del actor español en

el barroco, hipótesis y documentos. Madrid: Castalia. 